\title{
CAMINOS DE LA FICCIÓN DE FANTASĹA EN LA NARRATIVA ESPAÑOLA ACTUAL: RESULTADOS INICIALES DE UN PROYECTO
}

\author{
FranKLin GarcĹa SÁNCHEZ \\ Trent University (Canadá)
}

La riqueza de las formas de fantasía - es decir, de tendencia no realista - en la narrativa peninsular de nuestros días parece desmentir de manera rotunda un célebre planteamiento de Ramón Menéndez Pidal acerca de la irreprimible tensión de la literatura española hacia el realismo. Allí, en la introducción de Historia general de las literaturas hispánicas (1949), se observaba que "la «inventiva ibérica» siente un «invencible desvío» por «las quimeras fantásticas siempre que recoge sus íntimas fuerzas para producir los frutos más genuinos»"1. De este modo, al referirse a la "otra" literatura, el gran estudioso introduce el concepto de lo fantástico, aunque no deba pasarse por alto que lo hace pensando en una suma de diversos discursos no miméticos, ya que antes en su introducción englobaba en dicho fantástico lo siguiente:

1 I. Soldevila Durante, Historia de la novela española (1936-2001), I, Madrid, Cátedra, 2001, p. 122. 


\section{Franklin Garcla Sánchez}

"comedias mitológicas, escenas del mundo sobrenatural, novelas de prodigios, cuentos de espantos, sueños, coloquios portentosos..."2.

Nos encontramos, pues, ante una confusión conceptual muy corriente todavía hoy en la crítica peninsular, consistente en la imprecisión del deslinde entre lo maravilloso y lo fantástico, el cual, sin embargo, ya aparecía perfectamente resuelto en trabajos de Roger Caillois ${ }^{3}$. En el segundo de ellos, el más sintético y directo, “Les Trois styles de l'imaginaire", el campo de la fantasía quedará así repartido entre las vertientes de lo feérico o maravilloso, lo fantástico y la ciencia-ficción. De hecho, la investigación que estamos llevando a cabo bajo el mismo título de este trabajo (con omisión del añadido explicativo) demuestra que esos tres subcampos o territorios de la fantasía son intensamente explorados por la ficción española de las últimas décadas. Ahora bien, antes de establecer la constitución del corpus inicial de trece obras - doce de ellas novelas - de dicho proyecto, hemos de esbozar el proceso histórico-estético que hace posible la eclosión en nuestros días de semejante tipo de literatura.

Si nos situamos a la altura de los años cincuenta y consideramos, para comenzar, el caso de Industrias y andanzas de Alfanhuí (1951), de Rafael Sánchez Ferlosio, obra que no es fantástica como suele señalarse, sino lírico-maravillosa ${ }^{4}$, notaremos con Ignacio Soldevila que la sorpresa causada por la novela "contribuye eficazmente a revelar, en negativo, el vacío en que caían las pocas obras que, antes y después del Alfanhuí, intentaban salirse de la corriente general" ${ }^{\prime 5}$. Dicha corriente general es, por supuesto, la que constituyen el neorrealismo y el realismo social, y que perdurará hasta comienzos de los sesenta, década, como sabemos, en la que se produce la

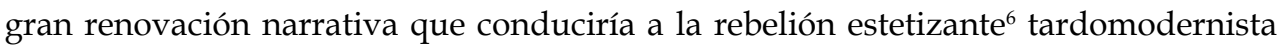
(llevada principalmente a cabo por la generación de 1968), con la cual, como observa Miguel Herráez, la novela española se incorpora al conjunto de la occidental ${ }^{7}$. Quedará así configurada la etapa experimentalista, la cual cabe situar entre 1968 y 1975 y que tendrá un decisivo impacto desinhibidor en las formas narrativas. No en balde su fruto

\footnotetext{
2 I. Soldevila Durante, op.cit., p. 121.

3 R. Caillois, Au Coeur du fantastique [1965], en Cohérences aventureuses, Paris, Gallimard, 1976 [1959], pp. 69-193; "Les Trois styles de l'imaginaire" (Introducción), en Les Chefs-d'œuvre de la science-fiction et du fantastique : Frankenstein, Dr. Jekyll et Mr. Hyde, Le moine, Paris, Cercle Européen du Livre, 1975, 4 pp. (libro sin paginación).

4 Vid., sobre este punto, el magistral estudio de Antonio Risco “El elemento maravilloso en Industrias y andanzas de Alfanhui, de Rafael Sánchez Ferlosio", Literatura y fantasía, Madrid, Taurus, 1982, pp. 173-227.

5 I. Soldevila Durante, op. cit., p. 125.

6 La expresión nos viene inspirada por Thomas Pavel en Representar la novela: El pensamiento de la novela, Barcelona, Crítica, 2005, p. 385.

7 Citado en S. Sanz Villanueva, “La vida cultural (1939-1975)”. Historia y crítica de la literatura española, 8/1: Época contemporánea: 1939-1975 (Primer suplemento), Barcelona, Crítica, 1999, pp. 3-23.
} 
más deslumbrante y genial, brote tardío de la generación del medio siglo, es Escuela de mandarines (1974), de Miguel Espinosa, texto en principio inclasificable, pero que todos reconocemos perfectamente como obra de fantasía, de imaginación alegórica o parabólica ${ }^{8}$, con desarrollos utópicos y distópicos ${ }^{9}$, y con manejo del cronotopo propio a la novela bizantina, es decir de espacio y tiempo abstractos, tal como perfila Pavel la modalidad parafraseando a Mijaíl Bajtín ${ }^{10}$.

Sin embargo, a la forma novelística de aquellos años le faltaba aún un elemento más, el de la legibilidad que le otorgaría el retorno a la narratividad - y con ello un cierto Nuevo Clasicismo -, operado hacia 1975 y que, como explicara con acierto Gonzalo Navajas, vendría a equilibrar los valores semánticos con los formales ${ }^{11}$. Si bien es cierto que la cultura del best-seller, espectacularmente floreciente en España hoy, se apoya con insistencia exacerbada en dicho polo de la narratividad, no lo es menos que lo más válido de la ficción peninsular de nuestros días sabe tomarse muy en serio las enseñanzas modernistas y tardomodernistas, al mismo tiempo que persigue la legibilidad que le permita alcanzar un ampliado público lector, como demuestra el corpus utilizado, que ya pasamos a describir:

-- Tres obras respectivamente emblemáticas de lo neofantástico (El desorden de tu nombre, 1988, de Juan José Millás), de lo maravilloso (Temblor, 1990, de Rosa Montero), y de la ciencia-ficción (Las puertas de lo posible: Cuentos de pasado mañana, 2008, de José María Merino),

-- una contribución al campo de la ciencia-ficción desde la orilla de la sátira menipea (Sin noticias de Gurb, 1991, de Eduardo Mendoza),

-- una fábula metafísica (Si al atardecer llegara el mensajero, 1995, de Soledad Puértolas),

-- una fantasía fantástico-expresionista (El viajero de Leicester, 1998, de Juan Pedro Aparicio),

-- una fantasía histórica, gótico-fantástica (La perra de Alejandría, 2003, de Pilar Pedraza),

-- una fantasía histórico-fantástica (Historia del Rey Transparente, 2005, de Rosa Montero), y

\footnotetext{
8 S. Sanz Villanueva, Historia de la literatura española, 6/2: Literatura actual, Barcelona, Ariel, 1984, p. 171.

9 I. Soldevila Durante, La novela desde 1936. Historia de la literatura española actual, 2, Madrid, Alambra, 1980, p. 443.

10 T. Pavel, op.cit., p. 10.

11 G. Navajas, Más allá de la posmodernidad: Estética de la nueva novela y cine españoles, Barcelona, EUB, 1996, p. 146.
} 
-- una serie de obras centradas en la generación de los noventa:

fantasía ucrónico-utópica: La sustancia interior (1996), de Lorenzo Silva,

fantasía lírico-maravillosa: El mundo en la Era de Varick (1999), de Andrés Ibáñez [con elementos de ciencia-ficción], y Labia (2001), de Eloy Tizón, metaficción fantástica: Alguien se acerca (1998), de Benjamín Prado, y

ciencia-ficción metafictiva: Nueva Lisboa (1995), de José Antonio Millán.

Se trata de un conjunto de obras creado sin a prioris, como no sean los que dictan los gustos y los límites de este lector, el cual cree apreciar las obras exigentes, con tal de que no comprometan más allá de lo razonable el disfrute de la lectura. Con relación a esto último, la obra más ardua resultó sin duda Nueva Lisboa, por la inaudita complejidad de su aparato de enunciación, inspirado en Las mil y una noches y en el Quijote, y por la angustiosa visión que destila de un mundo crepuscular ya vencido por las fuerzas de los universos virtuales de la robótica.

De dicho corpus y a los fines de este ensayo hemos de abstraer, con propósitos de análisis, cuatro obras escogidas en función de dos criterios: por un lado, su capacidad para proporcionar en conjunto un mapa ficcional donde estuviesen representados los tres grandes tipos de fantasía según Caillois, y, por el otro, su singular valor artístico. Son ellas, en este orden de estudio, La perra de Alejandría, Alguien se acerca, La sustancia interior y El mundo en la Era de Varick.

\section{LA PERRA DE ALEJANDRíA}

Como ya hiciera en su primera novela, Las joyas de la serpiente (1987), en la obra que nos ocupa Pedraza maneja la forma gótico-fantástica, vinculada ahora al tratamiento de una intriga histórico-filosófica de tiempo y espacio concretos: Alejandría en la segunda mitad del siglo IV, en momentos del Bajo Imperio en que la cultura helenística se extingue bajo el empuje del cristianismo ${ }^{12}$. Mundo “decadente" en el que, de manera específica, perviven precariamente el ritual dionisíaco y la filosofía cínica, la cual se expresa a través de la Secta del Perro, deudora del cínico antiguo Diógenes de Sinope. Nuestra utilización de "fantástico" líneas arriba, por cierto, ya venía inducida por el realismo implícito en la idea de una diégesis histórica y, precisamente, en dicha ocurrencia de lo fantástico en el terreno de su contrapartida necesaria, o sea,

12 Wilhelm Nestle afirma al respecto: “El estilo espiritual del período helenístico sigue en efecto vivo, hablando con rigor, hasta el final de la Antigüedad; por lo menos, hasta bien entrado el siglo III de la era cristiana" (W. Nestle, Historia del espíritu griego: Desde Homero hasta Luciano, Barcelona, Ariel, 1975, p. 245). 
el realismo, estriba la pertinencia estética o, si se prefiere, la competencia persuasiva ${ }^{13}$ de la propuesta de Pedraza.

Al repartirse entre los dos vectores que representan la mentalidad respectiva de los cínicos, por un lado, y de los adeptos de la cofradía de Dioniso, por el otro, la novela, así apoyada en una oposición de validez histórica en el nivel de la estructura de mentalidades, crea las condiciones para que lo fantástico vaya construyéndose de manera modular y dinámica entre los polos de la racionalidad y la superstición. En este sentido es absolutamente pertinente el que dicho foco racionalista se halle centrado en los cínicos, quienes, como entre otros ha mostrado Michel Onfray, constituyeron una de las más importantes corrientes antiplatónicas, hedonistas y materialistas de la Antigüedad ${ }^{14}$. Ahora bien, para mayor matización, buena parte del texto se halla narrativamente focalizada en un perro, léase "cínico", pero no un perro auténtico, no un racionalista puro, eje de la estrategia de despliegue de lo fantástico en la obra. Se trata del protagonista Mihal Gospod o, como se le llama en su exilio alejandrino, Bárbaro, príncipe de Dacia protegido de Elpidio, cabeza de la Secta del Perro en la ciudad. Quizás la mejor manera de aprehender su actitud hacia lo portentoso sea recogiendo su propia voz a finales del texto, cuando afirma: “Aquí no hago más que debilitarme, enamorarme como un viejo de comedia y no saber nunca si estoy viendo cosas reales o fantasmagorías"15. Veamos tres ejemplos que demuestran, efectivamente, cómo en La perra de Alejandría lo fantástico se construye en forma de montaje de una doble perspectiva en la cual, primero, el narrador, o Bárbaro a través suyo, registra nítidamente el portento como cualquier creyente, y luego se lo desmonta racionalmente, aunque sin anularlo.

El primer caso atañe al Rubio, personaje llegado de manera misteriosa a la ciudad, posiblemente en una nave del propio dios Dioniso, “que a menudo hacía notar su presencia en la ciudad" (14). De esta manera, un crepúsculo, Bárbaro sigue a dicho personaje por el puerto y presencia su participación como deidad en una ceremonia celebrada en Aguafuerte, al norte de Faro. Cierto, Bárbaro, que le está contando el episodio a Elpidio, ve al Hombre de Oro - ésa es la figura que emerge de las aguas más como encarnación de Alejandro el Magno que de Dioniso, pero ello sólo tiene que ver con la alegorización del portento, no con el portento mismo (19-20). Sin embargo,

\footnotetext{
${ }_{13}$ Ésta se produce cuando "la trama resulta finalmente creíble porque es internamente coherente: instaura mundos con su propia lógica y esto los hace convincentes" (A. Garrido Domínguez, "Introducción: Teorías de la ficción literaria: los paradigmas", en Teorías de la ficción literaria, Madrid, Arco/Libros, 1997, p. 26).

${ }_{14}$ M. Onfray, Las sabidurías de la antigüedad: Contrahistoria de la filosofía, I, Barcelona, Anagrama, 2007, pp. 131-140.

15 P. Pedraza, La perra de Alejandría, Madrid, Valdemar, 2003, pp. 238-239. En lo sucesivo toda referencia a la novela de Pedraza se hará en el cuerpo del análisis.
} 


\section{Franklin Garcĺa Sánchez}

la interpretación de Elpidio ("a él le sugería algo oscuro, perteneciente a la esfera de Dioniso" (20)) muestra la configuración terrorífica, es decir, gótica, de lo fantástico en el texto, la cual reposa en el terror a la epifanía del dios, a una de cuyas formas apunta el propio Elpidio: “la aparición de un dios bajo un aspecto humano" (21). En La perra de Alejandría, en definitiva, la realidad aparece sometida a un proceso de encantamiento motivado por un primitivismo desencadenado de sello dionisíaco.

El segundo ejemplo, una epifanía - como prodigio auténtico - causada por la filósofa Melanta, profundamente vinculada con Dioniso, pero al mismo tiempo por Hécate, ilustra dicho encantamiento fantástico de la realidad. De este modo, en una fiesta báquica, se hinchan el cielo y la tierra y una vasija de miel se desborda “espontáneamente" y se convierte en arroyo (38), de igual manera que la sangre fluye incontenible por entre los muslos de Melanta "empapando paños y los blancos manteles" (39). Bárbaro, por su parte, atestigua dichas "quiebras en las leyes de la naturaleza", aunque no sin escandalizarse "de la credulidad de los fieles y de su sumisión a una divinidad tan grosera" (41).

La siguiente ilustración y final concierne a San Antonio el anacoreta, con quien se encuentra Bárbaro en el desierto al regresar a Alejandría tras haber sido encarcelado y enviado a trabajar en unas minas. Ha visto "al extraño hombrecillo" (156) durmiendo, pero eso ha bastado para que la fuerza de sus visiones lo contaminen y logre ver por un instante la visión interior del santo, ya que ésta "rebosaba como la leche hirviente hasta quemar con sus salpicaduras a los que estaban a su alrededor" (156).

Así, la energía fantástica que genera la obra irá apoderándose de la totalidad del espacio representado, para alcanzar su paroxismo en la revuelta de los muertos del Hades, que, convertidos en sedientos vampiros, invaden Alejandría y la hacen añicos. Es ciertamente el fin del helenismo, pero, en una formidable pirueta final, el texto toma un giro ucrónico - en el sentido que suele dársele frecuentemente hoy de rectificación histórica mediante la explotación de una hipótesis no consumada - y el mundo que sucede al helénico no será el cristiano sino el suavemente pagano de Dacia, "un sitio duro pero bueno para vivir. No hay espectros, como éstos. Hay vampiros, pero son casi inofensivos y jamás atacan en masa" (253). Un universo, en suma, sin epifanías religiosas.

\section{ALGUIEN SE ACERCA}

La cuarta novela de Benjamín Prado se inserta de manera deslumbrante en el campo de la fantasía al reactivar con notables originalidad y riqueza temas esenciales de la historia de la ficción, particularmente vivos en nuestra época, como el 
desdoblamiento de la identidad, las fronteras porosas entre sueño y vigilia, y, de modo más incisivo aún, entre realidad ficticia y realidad fenomenológica. Todo lo cual se logra desde una visión creativa que privilegia lo imaginario mediante la plasmación de un mundo alterno que abona esta realidad, suplantándola. En este sentido, Alguien se acerca presenta semejanzas con una novela emblemática de la nueva narrativa española como El desorden de tu nombre. En cualquier caso, ambas deben ser consideradas como textos neofantásticos por cuanto asumen, para decirlo con Jaime Alazraki, "el mundo real como una máscara, como un tapujo que oculta una segunda realidad que es el verdadero destinatario de la narración neofantástica"16.

A continuación hemos de abordar el estudio de la obra desde dos ángulos antes señalados - el tema del doble y del Uno y el conflicto entre realidad ficticia y fenomenológica -. Otra característica esencial del texto, su creación de una realidad alterna de orden onírico, quedará subsumida en la primera aproximación.

\section{EL DOBLE Y EL UNO}

En el texto de Prado la problemática del desdoblamiento del ser se establece desde el arranque de la obra en estricta relación con la soledad y alienación del hombre contemporáneo, específicamente de un personaje más tarde identificado como "Unai Gómez Arieta, nacido en San Sebastián el 13 de julio de 1964, auxiliar administrativo, soltero, residente en Madrid... "17. La narración despliega una disposición clásica in media res, que en el caso de Alguien se acerca se funde armoniosamente con un estilo visualista de tendencia cinemática, el cual en los cuatro primeros capítulos incorpora intermitentemente, desde el emplazamiento de un sitio denominado Santa Lucía (probablemente Santa Lucía de la Sierra en su referencialidad real), la técnica del flasbac para contar un pasado muy cercano vivido en Madrid, aunque también, en el capítulo final de la serie, se vuelve hacia un pasado mucho más remoto, el de la niñez del personaje en la localidad de Treinta Cruces (32). De la alternancia Santa Lucía/Madrid surge un personaje de incierta identidad que, tras ser testigo en un bar madrileño de un crimen que pudo haberle costado la vida, y que lo convierte en "elhombre-que-no-había-muerto" (23), decide convertirse en otro.

Sin embargo, antes de que demos ese salto a la alteridad, ha de insistirse en la incertidumbre identitaria que aqueja a Unai. En otras palabras, quien intenta hacerse en otro ser, creándose una identidad diferente - el texto subraya claramente

16 J. Alazraki, “¿Qué es lo neofantástico?”, Teorías de lo fantástico, Madrid, Arco/Libros, 2001, p. 276.

17 B. Prado, Alguien se acerca, Madrid, Alfaguara, 1998, pp. 78-79. En lo sucesivo toda referencia a la novela de Prado se hará en el cuerpo del análisis. 


\section{Franklin Garcĺa Sánchez}

esta cuestión (20) - es un individuo propenso a salirse de sí mismo ("se sentía de pronto al margen, descolgado" (18)) y a perderse en una bruma onírica en la cual lo soñado se impone como la verdadera realidad: "Podía verlo todo tan claro como si de verdad estuviese allí; tan real que lo que no parecía cierto es que estuviera soñando" (14). De hecho, la serie de capítulos que hemos considerado por ahora concluye con el siguiente pensamiento del protagonista durante su viaje en autobús entre Madrid y Santa Lucía: “Cuando se despertara no sabría dónde estaba. Tal vez para entonces ni siquiera supiese quién era" (39).

De cara a lo que podríamos denominar déficit identitario del personaje, no han de pasarse por alto dos cuestiones relevantes, una en forma de respuesta a esa problemática del propio personaje, la otra como síntoma ambiental de su estar-enel-mundo. Nos referimos, por un lado, a la incorporación en el discurso de Unai de frases aprendidas en la novelística popular hard-boiled y de ciencia-ficción $(17,29)^{18}$ y, por el otro, a la alucinante presencia objetual desplegada en el relato - calificada por el propio protagonista como de una "importancia extraordinaria" (14) -, y que hace pensar irresistiblemente en la pintura alemana de la Nueva Objetividad durante la República de Weimar ${ }^{19}$.

Ambos temas son decisivos en la configuración semántica de la obra, pero aquí interesa el primero, pues el puente entre la identidad que quiere desaparecer y aquélla que se desea ver surgir se establece a través de la problemática intertextual y lectoral, con lo cual, por cierto, Alguien se acerca manifiesta su clara filiación cervantina. En efecto, durante su viaje hacia Santa Lucía, Unai ha adquirido tres obras con las que apuntalar el comienzo de su metamorfosis: La línea de sombra, de Joseph Conrad, El sótano, de Thomas Bernhard, y El árbol de la ciencia, de Pío Baroja (29).

De esa encrucijada de lecturas, pues, surgirá el Otro, y el voluntarismo de Unai hará que ese otro sea ni más ni menos que Andrés Hurtado (46). Lo que ocurre a la altura del capítulo 6, cuando el relato se afinca en el espacio del hotel al que ha llegado y donde ahora trabaja el protagonista, quien habrá de convivir con Andrés hasta la frase final del libro. No obstante, en este punto es indispensable notar que el mundo de Santa Lucía es, en fin de cuentas, un mundo alterno, como ensoñado. Por ello, no sólo Andrés irá haciéndose con retazos de Conrad, Bernhard y Baroja - a partir del capítulo 8 la intertextualidad adopta un sesgo vivencial y formativo cuando Andrés

18 Es obvio que la estilística de la novela negra norteamericana, cuyos indiscutibles maestros fueron Raymond Chandler y Dashiel Hammett, desempeña un papel de primer orden en el texto de Prado, principalmente en el manejo de los símiles. Se trata, sin embargo, de una dimensión colateral de nuestro trabajo.

19 F. García Sánchez, Territorios de fantasía: el realismo mágico y otras formas en narrativa, cine y pintura (manuscrito en prensa), 2009, pp. 11 sigs. 
incorpora a Conrad como materia de vida y afirma ser "el personaje de que hablaba la novela" (57) -, sino que el otro polo protagonístico de la obra, Sara, la mujer del dueño del hotel, el americano Fran Lowell, es, al mismo tiempo, emanación del universo glamoroso de Hollywood en su carácter de doble de Lana Turner y figura trasplantada de la segunda novela de Prado, Nunca le des la mano a un pistolero zurdo (1996) (111). De donde su halo misterioso de ente imaginario, como bien percibe Andrés al compartir con ella en cierto momento el espacio del bar del hotel: "Pero aquel cuarto le daba ahora la sensación de ser otro, alrededor de Sara: era un espacio irreal, extraño, un lugar sin límites, sin consistencia, parecido a una habitación en la que alguien está contando un sueño" (66).

Pero Sara no es sólo una fascinante encrucijada de cine y de novela (en esta segunda articulación habrá de señalarse que Andrés la ve como materia novelable (66)), es decir de imaginario, sino que, diegéticamente, también se halla en el centro de una intriga policíaca, pues esto es también la novela de Prado. Ahora bien, considerando que esta última dimensión es parcialmente metaficticia, hemos de referirnos por el momento a la intriga sólo en su proyección estrictamente diegética, dejando para el apartado siguiente el tratamiento de la problemática policíaca en su relación con el juego metaficticio instaurado entre el nivel autorial y el de los caracteres.

Lo que tenemos entonces es una intriga en la que intervienen Fran Lowell, su esposa, y un personaje misteriosamente desaparecido del hotel, un antiguo empleado del mismo, Davor, yugoeslavo de Croacia. Se trata obviamente de un triángulo amoroso, el cual se desdobla en un segundo si se incluye a Andrés, pero de él nos ocuparemos en otro momento por responder a la cuestión metafictiva antes observada.

El personaje de Davor posee relevancia, ya que actúa como una poderosa energía formativa sobre la personalidad de Sara por su notable cultura literaria, especialmente en lo que respecta a escritores praguenses. Efectivamente, había estudiado literatura en Checoeslovaquia "antes de que todo empezase" (62), y en la Universidad de Praga se había familiarizado con "Kafka, Bohumil Hrabal, Vladimir Holan, Siefert” (129). La obra y la vida de esos autores de una Praga ya mítica - a Davor le impresionó particularmente la historia de la mujer de Holan, quien le pagaba al carnicero con poemas de su marido (130) - son el inestimable bagaje literario que le aporta a Sara. Pero también está el cine, pues Davor sabe transmitirle su pasión por John Cassavetes y, así, en una novela en la cual la intertextualidad siempre adquiere un carácter activo, vivencial, ella le rinde su mejor tributo a su probable amante identificándose con un personaje del director norteamericano: “Ésa soy yo" (105). 


\section{Franklin Garcĺa Sánchez}

Esta línea argumental de sello policíaco tendría su desenlace en la posibilidad de que el Americano (Fran) haya asesinado a Davor y que luego haya ocultado su cadáver en un pozo tapiado. El comentario, de finales de la novela, proviene de un personaje de hablar reflexivo, pero no con fría distancia intelectual, sino acarreando la experiencia de la vida, al modo de determinados caracteres de la novela detectivesca americana, y de penetrante lucidez: el chofer de autobús que conoció bien a Davor y a los Lowell en las frecuentes paradas que hiciera en el hotel de la pareja durante sus viajes a La Coruña (204-205).

Se ve entonces cómo de manera magistral el autor ha instalado al nuevo Unai, es decir a Andrés, personaje virtual, de papel, en una verdadera encrucijada libresca y cinemática. Aunque es innegable que el propio Unai posee una identidad, digamos, gaseosa, él es, a pesar de todo, el ente envolvente del desdoblamiento. Ello explica que en el párrafo final de la obra Andrés quede incorporado y fundido en ese ser, lo cual ocurre, por un lado, con la reificación propia de las estéticas de vanguardia, y, por el otro, con el surrealismo, al que se rinde tributo a través de uno de sus indiscutibles pioneros, Pierre Reverdy.

La cosificación aparece en este final (208-209) con el retorno al relato de aquellos objetos del primer capítulo (13-14), tan importantes para el protagonista (nevera Balay, cadena de música Onkio, aspiradora Nilfisk, etc.), pero la diferencia es que ahora las cosas , al alejarse Unai de la casa rumbo a su trabajo, "se [van] quedando solas" (208), lo que haría pensar que la identidad de Unai se ha reforzado con la "devoración" de Andrés, quien es ahora parte integrante de él, como manifiestan las líneas finales en las que el narrador señala la presencia entre los objetos de un martillo con el cual Andrés perpetró un crimen, aún por detallar.

Dicha fusión que, según se ha visto, tiene su contrapartida en la liberación de los objetos - ahora, más que nunca, podemos imaginarlos plasmados en un lienzo con la alucinante precisión del ultrasharp focus de los hiperrealismos -, aparece paratextualmente puesta en relieve en el exergo con el que concluye la obra: “En lo profundo de un bosque/ dos hombres que venían de lejos se encontraron./ Al estar muy cerca el uno del otro/ ya no formaban más que uno/ y éste volvió solo a la ciudad./ Pierre Reverdy" (211, s/n). Unai: "uno", así queremos interpretar el nombre del protagonista. Sin embargo, ahora hemos de volver atrás en el texto y concentrarnos en el aspecto más sobresaliente de la novela, el de su tan original uso del pirandellismo en el tratamiento de la problemática ficción/realidad. 


\section{LA FANTASTICIDAD DE ENUNCIACIÓN}

Como otra obra de nuestro corpus general, El desorden de tu nombre, y también como Beatus ille (1986), de Antonio Muñoz Molina, Alguien se acerca se caracteriza por crear una trama en el nivel de la enunciación, con el establecimiento de fronteras entre realidad y ficción o, más específicamente, entre "autor" y entes ficticios; fronteras porosas donde se llevan a cabo travesías ontológicas. Sea como fuere, este orden de pirandellismo abre las puertas a la forma más original de fantástico, la única, por cierto, que se desempeña en la forma misma, la cual es perturbada, subvertida por, como ya dijimos, una trama, una historia: es, pues, el fantástico de enunciación.

El primer elemento de dicha trama, aunque previo a alguna potencial travesía ontológica, ofrece la ventaja de un doble aprovechamiento: no sólo pone en juego a dos actores de diferente nivel estructural - uno es el narrador manifestándose como autor implícito, el otro un personaje -, sino que asimismo interceptará la intriga policíaca de la que tratamos con anterioridad. El enunciado que a continuación se cita proviene del capítulo cuarto, cuando Unai se halla rememorando en Santa Lucía el viaje que lo llevó a ese lugar: “No podemos saber si aquel otro hombre quizá ya estaba allí; si el asesino en que iba a transformarse ya iba ocupándole poco a poco, centímetro a centímetro, igual que un líquido oscuro lleva lentamente una botella vacía" (31-32). Encontramos, pues, aquí la emergencia de dos polos: por un lado, un demiurgo que puede incluso pronosticar el futuro (cierto, podría objetarse que su omnisciencia no es absoluta, pero dicha duda queda disipada con la continuación de la cita: "Lo más probable es que él tampoco lo supiera" (32)), y, por el otro, al futuro Andrés que, se nos dice, será un asesino. De esta manera, penetramos, por primera vez en el decurso de nuestra lectura, en el tejido de la obra como construcción y creación; en otras palabras, el aparato metaficcional ha sido puesto en marcha. Pero, ¿matar a quién? El propio narrador se encargará de decírnoslo capítulos adelante, en la primera y contundente frase del capítulo 13: "Aquel domingo fue cuando Andrés supo que iba a matar a Fran Lowell" (99).

A estas alturas, por consiguiente, el autor implícito se encuentra en plena posesión del destino de su criatura, y, más aún, en un vuelco sorprendente de su discurso en el propio capítulo, pasa a la primera persona, se quita la máscara de persona ficta narrativa y desvela su ser histórico: “Si lo hubiera hecho [Si le hubiera dicho a Sara que no era Andrés Hurtado], esta novela no existiría y tal vez yo estuviese ahora mismo escribiendo sobre cualquier otra historia, pero al menos tampoco tendría por qué haber ocurrido nada de lo que vino después" (104). Henos, entonces, ante el "autor" y ante la primera travesía ontológica del texto, ejecutada por la misma figura en su doble enclave: ficticio y real. "Autor", pues sabemos que esta supuesta identidad 


\section{Franklin Garcĺa Sánchez}

histórica es devorada por la ficcionalidad del texto, como a su manera expresará Patricia Waugh: “The authors who step into their fictions [...] are locked into a system of endless regress. Their identity disappears the moment that it appears in the fictional text" ${ }^{\prime 20}$.

El resto del juego es el propiamente pirandelliano, puesto que la vertiente ontológica correspondiente a la ficción se activa y se torna hacia la realidad siguiendo dos etapas: toma de conciencia de la realidad del autor y amenaza de irrumpir en la misma. La primera de ellas se establece cuando, en medio de un diálogo con Unai/ Andrés, Sara expresa el temor de que el autor de Nunca le des la mano a un pistolero zurdo esté allí presente (“Quiero decir que puede que ahora mismo esté aquí, que haya estado escuchando toda esta conversación"(131)), y en la segunda, punto culminante del tipo de fantasticidad que analizamos, se asiste a la espectacular travesía de Andrés, lado criminal de Unai, "hacia este lado", el de, digamos, Benjamín Prado para amenazarlo de muerte: “- Y tú, si de verdad estás ahí, escribiendo todo esto... No importa dónde vayas. No importa dónde te escondas. Hagas lo que hagas, tú serás el siguiente” (150).

Luego, tras una nueva manifestación del protagonista de sus intenciones de ir a por el autor (“...dígame quién es y dónde puede estar, para que vaya a buscarle y le enseñe a quién tiene que dejar tranquila" (152)), el texto se trasladará a la instancia de la enunciación para continuar perfilando como pocos en las narrativas hispánicas la problemática ontológica del pirandellismo. Veremos así dos nuevas actuaciones del autor implícito hablando en su nombre propio, es decir en primera persona. En el primer caso desmonta la impersonalidad característica del rasgo canónico de la omnisciencia en el "estudio" psicológico de personajes: "Imagino que algo así es lo que debió de decirse en aquel momento a sí mismo" (156), mientras que en el segundo, de mucha mayor agudeza e importancia, se dirige al lector implícito y, a través suyo, claro, a nosotros, ya que a estas alturas las tríadas narrador/autor implícito/autor real y narratario/lector implícito/lector real actúan a rostro descubierto: “Créanme: si hubiera sido capaz de parar a Unai, hace ya algún tiempo que lo habría hecho. Pero la cuestión es que cada vez era más difícil y los dos lo sabíamos. Sin embargo, aún no iba a rendirme" (165). El fragmento es decisivo, ya que en esta pugna ontológica se colocan frente a frente, en un plano de nivelación, al mundo real y al ficcional, por lo que adquieren particular relevancia aquellas palabras de John Fowler en The French Lieutenant's Woman acerca de los mundos alternos ficcionales: “worlds as real as, but

\footnotetext{
${ }^{20}$ P. Waugh. Metafiction: The Theory and Practice of Self-Conscious Fiction, London and New York, Routledge, 1984, p. 142. Por su parte Lucien Dällenbach apunta certeramente al tipo de problemática que estudiamos cuando describe ciertas situaciones en las que se manifiesta una "mise en abyme de l'énonciation" (L. Dällenbach, Le Récit spéculaire: Essai sur la mise en abyme, Paris, Seuil, 1997, p. 100.
} 
other than the world that is. Or was" ${ }^{21}$. Por ello también este pasaje paradigmático hace pensar en el brillante perfil de Borges sobre las magias parciales del Quijote con su “juego de extrañas ambigüedades" 22 , que "sugieren que si los caracteres de una ficción pueden ser lectores o espectadores, nosotros, sus lectores o espectadores, podemos ser ficticios" 23 . Sea como fuere, Prado en su creación, como Fowles y Borges en sus comentarios, apuntan a lo mismo: al potente emborronamiento ontológico producido por el arte ficcional y su apuesta por el mundo alterno de lo imaginario.

Dicha intrusión autorial de orden metaficcional irá acentuándose a medida que avanza la narración, pero ello no hará nada por resolver la cuestión de la inestabilidad ontológica ya que, como ha observado Waugh "The more the author appears, the less he or she exists" 24 . En otros términos, por mucho que el demiurgo insista en sus poderes y los ejerza (es cierto que "nos" dice conocer perfectamente los planes de Unai para asesinar a Fran (165), y que evita el crimen infundiendo duda y confusión en la mente del protagonista (166)), y que esgrima con simpar desenvoltura su carácter de figura histórica, es decir, de Benjamín Prado, apuntando a su participación futura en avatares mediáticos de su relato (169-170), todo eso lo hace convertido ya en personaje de la novela. En fin de cuentas, como un personaje más de la ficción, su autoridad ha echado a rodar por tierra y ha perdido el control de su creación: "Porque ahora la historia estaba en otra parte, donde Unai la había llevado. Él y aquel otro tipo, Andrés..." (169).

Y, en efecto, Unai y Andrés han llevado la ficción por los derroteros de la novela policíaca y, en el plano metafictivo-pirandelliano de dicha intriga, el chivo expiatorio a eliminar es precisamente el "autor", convertido ahora en lastimosa figura perseguida y acorralada: "A veces pienso que Unai viene hacia aquí, imagino que tarde o temprano acabará encontrándome” (201). Tras lo cual vendrá la formidable rebelión de Andrés acusándolo de haber impedido la muerte de Fran: “- Lo has hecho tú. Tú escribiste esa escena. Hijo de puta. Lo has hecho tú para salvarle la vida. Tú me has quitado a Sara. La seguiste hasta Santa Lucía y ahora la has condenado a quedarse allí para siempre" (204). El texto proseguirá entonces con unas palabras (“Unai, Andrés. Mientras vienen hacia aquí (...) (204)) que bien podrían significar la muerte del autor, entendida como supresión de la perturbación ontológica, su permanencia en el texto "sólo" como persona ficta narrativa. De hecho, envuelta en esta suerte de Nirvana, la voz narrativa puede permitirse ahora narrar distanciadamente la fusión de las dos mitades del ser del protagonista en el capítulo final en que nos encontramos.

\footnotetext{
${ }^{21}$ Citado en P. Waugh, op.cit., p. 90.

22 J. L. Borges, "Magias parciales del Quijote", Obras Completas, Buenos Aires, Emecé Editores, 1974, p. 668.

23 J. L. Borges, op.cit., p. 669.

24 P. Waugh, op.cit., 134.
} 


\section{LA SUSTANCIA INTERIOR}

La sustancia interior es obra notable tanto a causa de la elaboradísima ascesis constructiva que la informa como de la riqueza y profundidad de sus valores semánticos. Por la manera armoniosa en que estas dos cualidades se funden en la obra, la novela de Lorenzo Silva alcanza una cota emblemática dentro de la nueva narrativa española.

La depuración constructiva aludida se relaciona con un procedimiento de la fantasía al que Katherine Hume denomina de "creación de nuevos mundos por sustracción y borrado" ${ }^{25}$. Dicho rasgo, en apariencia mínimo, cuaja con tal perfección en la novela, que le otorga límpidamente su carácter de fantasía. Para ser más concretos: La sustancia interior es obra de fantasía por el simple hecho de substraer todo tiempo y todo espacio reconocibles o, en otras palabras, por utilizar el cronotopo de la novela bizantina que, como señalamos con anterioridad, es de tiempo y espacio abstractos. Por supuesto, también podría pensarse en el romance - género al que pertenece la novela bizantina -, y recordar que la crítica ya ha señalado la importante proyección de dicha poética en la narrativa española contemporánea ${ }^{26}$. Sea como fuere, La sustancia interior lleva el rasgo observado hasta sus últimas consecuencias, ya que no sólo es un texto que transcurre en una Edad Media abstracta, sólo deductible como tal por la importancia del motivo de la catedral en construcción, sino, además, porque nos encontramos con una novela sin toponímicos. Doble articulación que hace de ella una ucronía, otro tiempo, y una utopía en el sentido etimológico estricto de "lo que no está en ningún lugar". Así ve la cuestión, por cierto, Santos Alonso, para quien la novela es "una fábula utópica y ucrónica" 27.

En lo que respecta a los valores semánticos, los mismos brotan del hecho de hallarse la obra en íntima relación intertextual con el universo de Kafka y, en particular, con aquellos textos que desarrollan temas como el del sometimiento del hombre a leyes, poderes o acciones cuyos designios permanecen ocultos o le son incomprensibles, exacerbando el sentimiento de un existir absurdo. Por supuesto, una parte apreciable de la obra del gran escritor checo se desenvuelve dentro de esa órbita, y sin dificultad vienen a la mente textos como El proceso (1914) ${ }^{28}$, El castillo (1922), “Ante la Ley” (1914), "La construcción de la Muralla China" (1917), "Sobre la cuestión de las leyes" (1920) y

${ }_{25}$ K. Hume, Fantasy and Mimesis:Responses to Reality in Western Literature, New York and London, Methuen, 1984, pp. 91-94.

26 D. Villanueva, “La «nueva narrativa española»", Historia y crítica de la literatura española, 9: Los nuevos nombres: 1975-1990, Barcelona, Crítica, 1992, pp. 286-289.

27 S. Alonso, La novela española en el fin de siglo, 1975-2001, Madrid, Marenostrum, 2003, p. 228.

${ }_{28}$ Sólo se dan las fechas de redacción de estos escritos de Kafka. 
“El escudo de la ciudad" (1920). Dicho profundo vínculo intertextual explica el carácter de fantasía distópica de la obra de Silva, la cual, por tanto, se desenvolverá en el eje utopía/distopía. Veamos la cuestión en cierto detalle.

$\mathrm{Si}$, en la primera frase de El castillo, K. llegaba al pueblo del castillo, en la de La sustancia interior el protagonista, Bálder, llega ante la catedral: “El extranjero se detuvo ante le catedral" 29 . El esquema diegético inicial es idéntico en las dos novelas: el forastero que viene de un lugar innominado a realizar una determinada obra, la talla de la sillería del coro en el caso de Bálder. Nótese que tan abstracto es el lugar de donde viene como aquél al que llega y, además, que carece de la opción de volver al primero: “- No puedo volver. Ya nada me espera allí" (120). Lo cual hace aún más angustioso este espacio teatralizado, asfixiante del Arzobispado, pues ése es su único nombre. A fin de cuentas, Bálder llega a una metáfora, la catedral, y al poderoso y maquiavélico sistema que la contiene, el de los doscientos canónigos encabezados por el Arzobispo. Lo que no puede imaginar el personaje es que el artista insumiso e idealista que él encarna, el que lucha por preservar su "sustancia interior", es decir, esa "sustancia íntima e incontaminada que le permitía pasearse por el infierno sin claudicar como habían claudicado todos" (288), acabará convertido en un arzobispo más.

Pero volvamos a la metáfora de la catedral, la cual, al ser concebida como utopía desmedida ("síntesis de todas las artes posibles, bajo la ordenación de un supremo proyecto arquitectónico que ha trazado un espacio por encima de todo conflicto" (188)), lleva aparejado desde su comienzo el germen del fracaso y la distopía, como observa el canónigo Tullius: “Hemos comprobado hasta la saciedad que bajo el disfraz de un orden se esconde el caos más indomable" (188). Pero, como esa obra, a la imagen de la Muralla China kafkiana, ha sido engendrada de manera "natural" (188) y "[v] a creciendo por sí sola" (347), hay que dejarla "que se extinga, a su ritmo premioso pero inexorable" (188). Ese caos que, para su desgracia, trata de acotar Bálder es el monstruo que le devora la sustancia interior.

No entraremos en los detalles de su paulatina caída, sino que nos limitamos, utilizando una imagen a lo Joseph Conrad muy presente en la narrativa española contemporánea $^{30}$, a su viaje al corazón de las tinieblas, que se pone en marcha con su decisión de visitar el laberinto de los pisos superiores del palacio arzobispal, donde viven estos tres personajes clave: Náusica, el arquitecto y el Arzobispo, los cuales constituyen, en definitiva, un núcleo, ya que Náusica es la hija del Arzobispo y, de

29 L. Silva, La sustancia interior, Barcelona, Ediciones Destino, 2004, p. 13. En lo sucesivo toda referencia a la novela de Silva se hará en el cuerpo del análisis.

30 La encontramos, por ejemplo, en fantasías como El año del francés (1986), de Juan Pedro Aparicio, y Temblor. 


\section{Franklin Garcla Sánchez}

niña, fue desflorada por el arquitecto, condenado por ella misma más tarde a vivir recluido en el palacio, ya despojado de toda dignidad artística.

Náusica, personaje formidable por el que penetra lo fantástico en esta fantasía sobre la existencia y el sentido ético de estar en el mundo - preservar la sustancia interior ante la Ley y el poder -, se convierte, con su belleza extraña y devoradora, en la materia onírica de Bálder - reminiscencia quizás de la relación con el mundo de los sueños de la hija de Alcínoo -, la cual desplaza y destruye su sustancia interior. Esta belleza "salvaje", de "cegadora melena rubia", "afilada como un cuchillo" (183) y de "pechos infantiles" (238), esta "aciaga criatura" (381), a quien el protagonista ha ido a matar para que ella no lo mate o también para recuperar su ser íntimo, se muestra, por el contrario, sumamente dócil, portadora en su rostro melancólico de "un misticismo inédito" (386). Hacen, pues, el amor, él no se decide a inmolarla, y es apresado y encerrado en una mazmorra por orden del Arzobispo, no de ella.

Antes de dicho episodio en que magistralmente se trenzan Eros y Tánatos, ha tenido lugar la visita de Bálder al arquitecto. Se trata del hermoso capítulo "El sueño del arquitecto", en el cual, como luego en los dos capítulos siguientes y finales, la obra despliega con gran fuerza e intensidad el tema del doble, primero en relación con el arquitecto, más tarde con el Arzobispo, en un crescendo que conduce a la aniquilación de Bálder.

El espejo que tiene ante sí el protagonista cuando visita al arquitecto - y que de manera discursiva queda recortado en esta constatación: "El hecho es que me comparo contigo y apenas encuentro algo que nos distinga" (371) - es, por un lado, el del artista desengañado ante la imposibilidad de llevar a cabo una obra imposible, y, por el otro, el del hombre que ya sucumbió al poder destructor de Eros en la figura de Náusica. En efecto, en este capítulo la obra es plasmada como una alegoría de la creación artística y de sus quimeras, por lo que no en vano el arquitecto se proyecta como un trasunto del goticista visionario Eugène Viollet-le-Duc (1814-1879). La presencia en el centro de una sala inmensa de la reproducción a escala de la catedral da una excepcional forma icónica al abismo que separa las demenciales aspiraciones del artista ("Y en el centro, alcanzando una altura que duplicaba la de las cuatro [torres] que habían sido alzadas, una última que culminaba aquella desmesura desafiando todas las leyes constructivas de las que Bálder tenía noción" (363)) de la "fracción minúscula" de lo realizado, “a pesar del gentío de operarios y artistas" (363). Ahora bien, el desengañado artista ("Yo había proyectado una catedral magnífica, y de pronto me encontraba empozado en una empresa tediosa, infinita" (368)) sigue patéticamente retocando el proyecto para no enloquecer (366). Es cierto que a finales del encuentro el arquitecto alberga la ilusión de que su obra sean la reproducción y los incontables bocetos que cuelgan 
de las paredes, y que ello hace de él, de nuevo, un artista, pero Bálder, personaje de pulsiones $y$, en ese sentido, profundamente romántico, rechaza semejante consolación y marcha a su pérdida, o sea, hacia Náusica y el vacío, pues:" - Ya no soy un artista, ni lo seré nunca. La obra me ha destruido, como destruyó tu proyecto" (377).

El Arzobispo, por su parte, representa el destino que espera a Bálder, quien será un eslabón más de la infinita cadena de extranjeros que llegan al Arzobispado, germinan a la hija del Arzobispo y suceden a éste a su muerte. Sin embargo, como corresponde a la lógica del absurdo a que obedece el relato, este hombre de sotana negra es el simple simulacro de un poder abstracto e irracional: "Es la investidura la que me gobierna a mí" (400). Impersonalidad que se halla en el centro del primero de los cuatro fragmentos que constituyen el capítulo final, "La venganza". Allí vemos, efectivamente, al Arzobispo ajustándose la mitra con sus "dedos extraños" (406), en medio de la ceremonia de su ordenación. No obstante, ese Arzobispo no es otro que Bálder, quien se abstrae de su entorno para repasar lo ocurrido en los últimos diez años, dando así lugar a la segunda pieza del montaje, en forma de analepsis, un fragmento que delinea el proceso de ordenamiento de Bálder como canónigo hasta la muerte del Arzobispo. La noche en que esto ocurre cristaliza su idea de venganza: "debía infligir al monstruo que le había devorado las entrañas el mismo daño que a él le había sido infligido" (415). Se retorna entonces a la posición temporal del rito de entronización y ahora el Arzobispo se dirige a sus súbditos formulando el propósito de finalizar la catedral, es decir, el monstruo. Ésa sería su venganza: terminar la catedral para así ponerle fin al Arzobispado, que ya no tendría razón de existir. Y no sólo eso, sino que también recuperaría su identidad auténtica y volvería a su patria (418). Pero la brevísima cuarta pieza del montaje liquida toda veleidad de salvación, ya que muchos años después, con la catedral inacabada, Bálder ha de aceptar la acción divina, que supo, "tras el esfuerzo de elegirle, vincularle a su inextricable proyecto" (419).

\section{EL MUNDO EN LA ERA DE VARICK}

La novela de Andrés Ibáñez, por su lado, es la obra más brillante y ambiciosa del corpus. No sin razón Santos Alonso ha podido considerarla como "uno de los experimentos literarios más fascinantes y revitalizadores del panorama narrativo

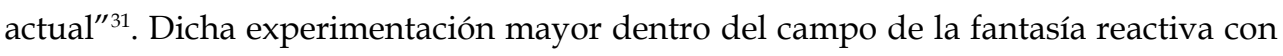
simpar aliento el fondo simbolista y surrealista de la literatura occidental, dándole todo su sentido a aquella penetrante expresión de "reencantamiento de la realidad", utilizada por Ricardo Gullón en sendos trabajos a propósito de la obra narrativa de José María Merino y de otros escritores del noroeste español como Luis Mateo Díez

31 S. Alonso, op.cit., p. 277. 
y Juan Pedro Aparicio ${ }^{32}$. Así, pues, el grupo leonés reencanta el tiempo y el espacio asturleoneses, pero también, entre otros tantísimos ejemplos, Carlos Ruiz Zafón reencanta a Barcelona, Eloy Tizón a Madrid y Antonio Muñoz Molina a la generación del 27 al modo aubiano, mediante el incisivo expediente del apócrifo. Y como, en fin de cuentas, la emergencia de la fantasía en España es una cuestión de reencantamientos, Andrés Ibáñez reencanta en su novela no sólo nuestra realidad, sino el universo todo. $\mathrm{O}$, para decirlo con el surrealismo, reencanta el universo desde esta realidad, en la que late la posibilidad de lo maravilloso y de la poesía. De este modo, la propuesta de Ibánez incorporará como dos caras de una misma moneda: lo maravilloso surrealista y el culto de la belleza al modo, digamos, juanramoniano. En verdad, El mundo en la Era de Varick y Labia poseen un estrecho parentesco, pero en la segunda lo maravilloso es feérico y se da en un segundo grado narrativo, no como concreción.

Veamos la manera como en El mundo en la Era de Varick se crea lo maravilloso como una suprarrealidad latente en el aquí y ahora, el cual se halla primordialmente localizado en la ciudad de Nueva York, aunque con importantes ramificaciones en otras latitudes: Madrid, Estambul y Fontainebleau. Estos tres sitios son el enclave de lo maravilloso y del encantamiento del mundo, y no en vano los dos primeros son espacios experimentados desde ciertas potentes subjetividades, las de Marcelo y Rita, como Terra Merveille, y en Fontainebleau se halla, sin más, Termerveil, territorio mítico donde se encuentra el Monasterio Perdido. Hacia este espacio, decisivo en la economía simbolista de una obra impregnada de la nostalgia de otros mundos, encaminarán sus pasos en las páginas finales los Variborgs supervivientes de la Era de Varick, período de las últimas décadas del siglo XX en que el extraterrestre de ese nombre insufló hedonismo y un potente pensamiento salvaje - negación del pensamiento asociativo, Armkidjj - sobre Terra.

Rita y Marcelo, llamados Varibabies, son la encarnación de lo maravilloso en Terra, pues lograron experimentarlo desde la infancia en lo más intimo de su ser. En el caso de Marcelo dicha pulsión es "el viento de los mundos" que soplaba desde la tarde en que logró ver desplegarse en el cielo "la gran rosa del Planeta de los Sueños" ${ }^{\text {"33. Estos }}$ Variborgs ahora neoyorquinos son hacedores de belleza: ella, sublime bailarina que se inspira en Isadora Duncan, y él, novelista sobre el que se ejerce el magisterio, entre otros, del mítico autor de Paradiso, José Lezama Lima (494, 497-499), de un tal Marcelo

32 G. Gullón, "El novelista como fabulador de la realidad: Mayoral, Merino, Guelbenzu", y "El reencantamiento de la realidad: La orilla oscura, de José María Merino, en Nuevos y Novísimos: Algunas perspectivas críticas sobre la narrativa española desde la década de los 60, Boulder, Society of Spanish and Spanish-American Studies, 1987, pp. 71-81 y p. 61.

33 A. Ibáñez, El mundo en la Era de Varick, Madrid, Ediciones Siruela, 1999, p. 507. En lo sucesivo toda referencia a la novela de Ibáñez se hará en el cuerpo del análisis. 
Proust (495), y de una obra apócrifa, Vida en el planeta Demonia, de W. Lycaeides, obraespejo de la novela que leemos. Rita y Marcelo son, pues, poderosos emblemas de la búsqueda de lo maravilloso y, en un vínculo indisoluble, de la poesía: “El único más allá en que creía [Marcelo] era el más allá de la belleza al que nos transporta el olor de las rosas y la agradable asimetría del poema perfecto" (257).

Entre los mundos paralelos que rodean a Terra descuella, precisamente, el de Demonia, su planeta análogo. Hemos de concentrarnos ahora en la parte que trata de dicho planeta, titulada "Memorias del Barrio de los Magos por «Verdamar»", por dos razones: por tratarse de una pieza magistral del arte narrativo, y por constituir el segmento de la obra donde mejor se puede calibrar el vibrante homenaje al Modernismo (en el sentido anglosajón del término) que la misma pone en juego. Lo cual haría de la novela de Ibáñez, con su absoluto descrispamiento de cara a lo moderno, una obra neomoderna.

El extenso relato que nos ocupa (299-412) es narrado por la gata Octaviana María o Verdamar - su nombre mágico -, de lenguaje exquisito, ya que es poeta, y sobre todo, de "Vista Agudísima" (312). La enunciación, por tanto, apela al maravilloso feérico, el de los animales que hablan, pero sin detenerse ahí, ya que simultáneamente se incorpora un rasgo eminentemente vanguardista, el de la mirada nueva que devuelva al objeto su prístina condición. Es, claro está, la mirada que siempre persiguieron los surrealistas, la del encantamiento maravilloso del mundo. Pues bien, ésa es la mirada que contará Demonia, que es, justamente, el lugar donde "se hacen realidad los sueños de Terra" (321). Ha de señalarse, sin embargo, que la deliciosa gata no está narrando en Erumburgo, su ciudad en Demonia, sino desde la Gran Máquina, artefacto salido de Terra con dos mil tripulantes rumbo a Orplid, un lugar inexplorado de Demonia, con el fin de escapar del poderoso influjo de Terra sobre su planeta análogo (374-375).

La mirada de Verdamar es ciertamente agudísima, pero también está llena de gracia, humor e ironía, rasgos idóneos para la diseminación desde la instancia autorial de toda una red de preferencias y rechazos artísticos. Las preferencias son obvias: se refieren siempre a los modernos. En lo que respecta a los rechazos, el más contundente implica al realismo, como cabía esperar de una obra de ferviente sensibilidad irrealista. Veamos ejemplos de las dos vertientes.

Al espíritu modernista se le rinde tributo en un arco que abarcaría desde Baudelaire, cuyo gato Antínoo es el amante de la gata, hasta los surrealistas, cuyos nombres son de los primeros nombres reales proferidos con todas sus letras en el texto: “André el Bretón [con leve giro humorístico], Alfred Jarry, Raymond Roussel, Robert Desnos, Paul Eluard (...)" (348). Y, en el centro del arco, Proust, que aparece sólo 


\section{Franklin Garcla Sánchez}

como Marcel, y que es claramente la proyección, el sueño, de Marcelo en Demonia. De esta manera, el escritor será paródicamente homenajeado al convertirse su gran obra maestra en Les Colombes Poignardées, y se le celebrará desde su propia voz en una nota al texto de Octaviana María, en la que defiende con fervor el arte de la digresión, como réplica a una nota previa de la dueña de la gata quejándose de "esos paréntesis interminables" (323).

El reverso de la celebración de los modernos lo constituye la repulsa de las perversiones del realismo que convierten "el arte delicioso de la Escuela de los Detalles (...) en las tediosas enumeraciones de la Escuela de los Catálogos" (312). Otras dos "escuelas" realistas, el "realismo materialista" - que suponemos sea el objetual - y el "realismo mágico", son igualmente rechazados por tratarse de modas apartadas "del cultivo de la Atención y del Amor" (328). Rechazo que se esclarece en este otro planteamiento nodal de la narradora: "En cierto modo, sólo los malos escritores pintan la vida como verdaderamente la vivimos, y su falta de atención y de poesía se corresponden perfectamente con el Estado corriente en que pasamos la mayor parte de nuestra existencia" (326). Por consiguiente, la problemática va más allá del realismo y se convierte en una cuestión sobre el qué percibir de la realidad y con qué intensidad y profundidad. De ahí que la gata celebre la "visión del Ojo externo", cristalizada solamente en algunas páginas de los grandes maestros, y que representa "el despertar pineal de nuestra percepción dormida que nos permite vernos a nosotros mismos como realmente somos y ver el mundo como realmente es" (326). Por supuesto, éste es el tipo de mirada que ha intentado Ibáñez en su novela y, ateniéndonos a la distinción de raigambre romántica establecida en el propio libro entre fantasía e imaginación - la primera es parasitaria, la segunda de una radical exigencia -, se trata de una mirada de la imaginación, ya que sólo ésta "permite pensar por fuera de las palabras y la lógica para llegar [al] «ángel»" $(480)^{34}$.

Quizás sea demasiado pronto para establecer con cierta certeza en qué medida alcanzó el autor la escritura trascendental que ambiciona, pero sí sabemos que su rica creatividad, fervientemente reinvindicadora de la estética de las correspondencias del simbolismo europeo, ha abonado los territorios de fantasía de la literatura española de hoy. Por lo cual queremos postular el carácter emblemático para nuestra investigación de un texto como éste, que se situaría en la avanzada neosimbolista que creemos ver en la recomposición del campo ficcional ocurrida en la narrativa española de las últimas tres décadas. Simbolistas son, en efecto, el reencantamiento del mundo al que nos

\footnotetext{
${ }^{34}$ Nos parece obvio que la fantasía a la que alude la novela de Ibáñez es el fancy del inglés y no el fantasy de los discursos literarios. Es probable que esta fantasía del autor español corresponda al "pensamiento asociativo" antes señalado y que la condena del realismo mágico provenga de esa "pobreza" de pensamiento.
} 
refiriésemos en su momento, y la radical apuesta antirrealista por mundos alternos e imaginarios, que de un modo o de otro se percibe tanto en las cuatro obras analizadas como en el corpus in extenso. Así, dentro de él, y para ilustrar la cuestión de la manera más ceñida posible, habría que señalar El viajero de Leicester, que coloca en el centro de su red semántica al filósofo Emanuel Swedenborg, figura tutelar del simbolismo, cuya obra constituyera el basamento de la idea de las correspondencias de Baudelaire, expuesta en el soneto "Correspondances" de Les Fleurs du mal (1857), y aplicada en otros poemas del libro. Y fuera del corpus, pero en el mismo período que estudiamos, La isla inaudita (1989), de Eduardo Mendoza, hace con Venecia lo que Georges Rodenbach había realizado con Brujas en Bruges-la-Morte (1892), o sea, convertir a una ciudad en puro estado subjetivo ${ }^{35}$. Por supuesto, todavía debemos continuar decantando el vínculo establecido entre el simbolismo histórico y un neosimbolismo de la narrativa española de nuestros días, pero de lo que sí no cabe duda es de cuál es a partir de ahora la piedra angular del proyecto: el área estética de los simbolismos.

\section{BIBLIOGRAFÍA}

ALAZRAKI, JAIME. “¿Qué es lo neofantástico?” en D. Roas (ed.), Teorías de lo fantástico, Madrid, Arco/Libros (Lecturas), 2001, pp. 265-82.

ALONSO, SANTOS, La novela española en el fin de siglo, 1975-2001, Madrid, Marenostrum (Estudios y Ensayos 3), 2003.

BORGES, JORGE LUIS, “Magias parciales del Quijote”, Obras Completas, Buenos Aires, Emecé Editores, 1974, pp. 667-669.

CAILLOIS, ROGER, Au Coeur du fantastique [1965], in Cohérences aventureuses, Paris, Gallimard (Idées), 1976, pp. 69-193.

--- “Les Trois styles de l'imaginaire" (Introducción). Les Chefs-d'oeuvre de la sciencefiction et du fantastique: Frankenstein, Dr. Jekyll et Mr. Hyde, Le moine, Paris, Cercle Européen du Livre, 1975, 4 pp. (libro sin paginación).

DÄLLENBACH, LUCIEN, Le Récit spéculaire: Essai sur la mise en abyme, Paris, Seuil (Poétique), 1977.

GARCÍA SÁNCHEZ, FRANKLIN, Territorios de fantasía : el realismo mágico y otras formas en narrativa, cine y pintura (en prensa) , 2009, 201 pp.

GARRIDO DOMÍNGUEZ, ANTONIO, “Introducción: Teorías de la ficción literaria: los paradigmas" en A. Garrido Domínguez (ed.), Teorías de la ficción literaria, Madrid, Arco/Libros (Lecturas), 1997, pp. 9-40.

35 Paralelismo inspirado en observaciones de Jean-Nicolas Illuoz sobre la novela del escritor belga (J. N. Illuoz, Le Symbolisme, Paris, Le Livre de Poche, 2004, p. 125). 
GULLÓN, GERMÁN, “El novelista como fabulador de la realidad: Mayoral, Merino, Guelbenzu” y “El reencantamiento de la realidad: La orilla oscura, de José María Merino", R. Landeira y L. T. González-del-Valle (eds), Nuevos y Novísimos: Algunas perspectivas críticas sobre la narrativa española desde la década de los 60, Boulder, Society of Spanish and Spanish-American Studies, 1987, pp. 59-70 y 71-81.

HUME, KATHRYN, Fantasy and Mimesis: Responses to Reality in Western Literature, New York and London, Methuen, 1984.

IBÁÑEZ, ANDRÉS, El mundo en la Era de Varick, Madrid, Ediciones Siruela (Libros del Tiempo 114), 1999.

ILLOUZ, JEAN-NICOLAS, Le Symbolisme, Paris, Le Livre de Poche (Références), 2004.

NAVAJAS, GONZALO, Más allá de la posmodernidad: Estética de la nueva novela y cine españoles, Barcelona, EUB, 1996.

NESTLE, WILHELM, Historia del espíritu griego: Desde Homero hasta Luciano (Traducción de Manuel Sacristán), Barcelona, Ariel (“Convivium”), 1975 (2da. ed.).

ONFRAY, MICHEL, Las sabidurías de la antigüedad: Contrahistoria de la filosofía, I (Traducción de Marco Aurelio Galmarini), Barcelona, Anagrama (Colección Argumentos 361), 2007.

PAVEL, THOMAS, Representar la existencia: El pensamiento de la novela (Traducción de David Roas Deus), Barcelona, Crítica (Letras de la Humanidad), 2005.

PEDRAZA, PILAR, La perra de Alejandría, Madrid, Valdemar (Gran Diógenes 1), 2003. PRADO, Benjamín, Alguien se acerca, Madrid, Alfaguara, 1998.

RISCO, ANTONIO, Literatura y fantasía, Madrid, Taurus (Persiles 135), 1982.

SANZ VILLANUEVA, SANTOS, Historia de la literatura española, 6/2: Literatura actual, Barcelona, Ariel (Letras e Ideas, Instrumenta), 1984.

---“La vida cultural (1939-1975)” Historia y crítica de la literatura española, 8/1: Época contemporánea: 1939-1975 (Primer suplemento), Barcelona, Crítica (Páginas de Filología), 1999, pp. 3-23.

SILVA, LORENZO, La sustancia interior, Barcelona, Ediciones Destino (Booket 2140), 2004 (2da. ed.).

SOLDEVILA DURANTE, IGNACIO, La novela desde 1936. Historia de la literatura española actual, 2, Madrid, Alhambra (Estudios), 1980.

--- Historia de la novela española (1936-2001), I, Madrid, Cátedra (Crítica y Estudios Literarios), 2001.

VILLANUEVA, DARÍO, "La «nueva narrativa española»", Historia y crítica de la literatura española, 9: Los nuevos nombres: 1975-1990, Barcelona, Crítica (Páginas de Filología), 1992, pp. 285-292.

WAUGH, PATRICIA, Metafiction: The Theory and Practice of Self-Conscious Fiction, London and New York, Routledge (New Accents), 1984. 